ARTICLE

Received 15 Jul 2016 | Accepted 28 Mar 2017 | Published 28 Apr 2017

DOI: $10.1057 /$ palcomms.2017.29

OPEN

\title{
Drama for developing integrity in Higher Education
}

\author{
Adam Jagiello-Rusilowski ${ }^{1}$
}

\begin{abstract}
Developing academic integrity is context-based and ineffective through formal courses. The article explores the meanings of academic integrity, reviews literature on educational strategies towards its development and presents the design and results of the author's research on how drama may augment development of academic integrity of MBA students in the innovation camp setting. The philosophical framework for integrity learning and its perception by students comes from Bakhtin's dialogical theory of self and critical pedagogy of Freire. Drama is offered as a learning medium which provides context to explore multiple perspectives and imaginary dialogues of characters who may take ethically dubious positions. Assessment of integrity at the input stage and after completion of the drama sessions was two-fold. A self-efficacy test was used for standardized measurement and sociometry was applied to asses four areas of ethical education: (1) being sensitive to ethical dilemmas at stake; (2) reasoning/reflective skills and; (3) motivation/conviction to give over other considerations to the values, principles, or ideals that prompt the action to be taken; (4) strategizing to act ethically. The findings suggest that drama effectively augments the development of otherwise stable integrity of MBS students by making them more optimistic about their courage to adhere to values in face of adversity, especially to defend diversity as a human right and pre-condition for innovation. This article is published as part of a collection on integrity and its counterfeits.
\end{abstract}

\footnotetext{
${ }^{1}$ Social Sciences, University of Gdansk, Gdansk, Poland Correspondence: (e-mail: arusil@ug.edu.pl)
} 


\section{Definition and philosophical framework of integrity}

- he Latin root "integer" or "integritas" mean whole, entire, consistent. There is a long tradition in moral philosophy of defining integrity as virtues constituting individuals or groups whose declarations and acts are both aligned with a compatible moral purpose (MacIntyre, 1981). A person with integrity is somebody whose words and practices are convincing to self and others. She or he shows stability and deliberate commitment to moral ends and means (Scherkoske, 2012).

In a broad sense integrity is about "living up to your beliefs". People, however, believe contradictory things, some beliefs are stronger than others. Some are shared by groups who create dominant cultures; alternative ones may be promoted by strong characters. Beliefs are translated into actions: they are verbalized, reflected in behaviour or quality of performance. Beliefs are also withheld so not saying something, hiding, resisting or being passive is also an act. Integrity's function, therefore, is both to give strength to characters and at the same time to engage in a dialogue about the value of their beliefs as such and as potential for action (Pappas, 2015).

Since Aristotle it has been assumed that integrity is social whichever level it is analyzed: personal, situational, institutional or systemic (Babbitt, 1997). In opposition to the Kantian search for the universal application of abstract moral concepts, integrity is evaluated in terms of how individuals or cultures act towards each other in specific temporal and special contexts. Written narratives both of moral philosophy and literary fiction are vital records and educational sources for deliberations of integrity but the ability to rationally interpret culturally valued texts or even personal ethical stories authored by specific individuals cannot in itself guarantee enough guidance for keeping integrity when faced with confrontation.

The social sense of integrity lies not so much in adherence to shared values when the stakes are high or when actions affect large communities, as the narratives may imply. Integrity means that our everyday actions are compatible with basic moral values in relation to other people even in the most prosaic moments of our interactions. Aristotle's interest in moral responsibility for consequences of actions and achievements earned by virtuous deeds is extended by Bakhtin's (1990) theory of "answerability". Moral integrity from this perspective means the ability to reconcile the judgements on the consequences of our own or somebody else's actions with the evaluations of ethical feedback from those affected by our actions. It is a dynamic and dialogical process rather than the state of being virtuous. Integrity in this interculturally interconnected sense requires continuous mindfulness of the subjects involved, which answer to each other whenever they change their positions to unfolding events and their socially constructed meanings.

Bakhtin conceptualized "answerabilty" as a multi-voiced reality which progresses like a good (Dostoyevsky's) novel. Characters (as well as critical readers) benefit from engaging in a dialogue which is not controlled by the omniscient narrator who juxtaposes certain fixed positions and facts. The dialoguing agents are transformed through each other's responses, a dynamic cycle which impacts on the interlocutors' consciousness or perspective. One's individual attitude and ethical stance are confronted when characters initiate a dialogue, offer a statement or question and expect a reply which produces actual change in the way they think. The dialogical partner is always in an intense relationship with the other, Bakhtinian dialogue, however, "resists closure or unambiguous expression, and fails to produce a 'whole'. It is a consciousness lived constantly on the borders of other consciousnesses" (Robinson, 2011). Bakhtin promoted the idea of "creativity borderland made up of many worlds", all equally capable of expressing themselves and conceptualizing their objects. Everything is said in response to other statements and in anticipation of future statements" (Robinson, 2011).

The relational view of ethical self (Bakhtin, 1986) is also based on the concept of "outsidedness"-the ability to change perspective from ego- or ethnocentric to the views assumed by those effected by subject's actions. In contrast to the justice system integrity requires not just retrospective scrutiny of acts against the principles (of law) and application of social norms but ongoing reflection on what is at stake for those involved in the particular event. What really counts ethically for Bakhtin is the living experience of the unique event, the human conscious improvising with thoughts, feelings, words, gestures for which one takes responsibility and towards which one orients the performance (Handley, 1993).

Bakhtin finally offers the concept of "chronotope", meaning the unity of time, space, and the value system in which events occur. The values system in a given "chronotope" imposes the rationale of human interaction. People constantly struggle against external definitions of their thoughts and actions, which may have a deadening effect on their autonomy. The paralysis of agency caused by the outdated "chronotope" becomes the root of their failure, which is perceived as the inability to meet social expectations. Integrity can only be actualized through a free discursive act, and not in a pre-defined context. Engagement in dialogue, therefore, builds both integrity and resilience, either as the ability to see the benefits of distancing to pressure or even openly failing to satisfy general social norms for the sake of "answeribility" in a space and time with the community of dialogic partners. Bakhtin redefines the failure and prevents the fear of failing through the liberation of the ego or the ethnocentric self, bounded by authority and an estranged value system. The dialogical self becomes resilient through the strength and support provided by the diversity of interlocutors, and the shared flexibility of perspectives occurring spontaneously along the unfolding situations instead of predictable standards. Resilience and integrity are not just about the participation in the mainstream societal structures of support but the courage to risk failure to challenge any structures limiting growth. They are dialogically learnt abilities which help the individual to understand why the specific offer is developed or rejected, or what is the sense and future potential of the mistake revealed in the interaction. Since creative thoughts and solutions found through dialogue have no single author, so analogically there is no need to blame anybody for the failure unless it is the unethical system itself.

Freire's pedagogy provides the theoretical framework in line with Bakhtin's concepts because it defines daily life experiences as valuable resources which learners use to relate to while they face the educational content, including prescriptive ethics. Freire recognized that education must be related to the future which offer the next generation a life that leads to the deepening of freedom and social justice and" concern with keeping the forever unexhausted and unfulfilled human potential open, fighting back all attempts to foreclose and pre-empt the further unraveling of human possibilities, prodding human society to go on questioning itself and preventing that questioning from ever stalling or being declared finished." (Bauman, 2001) Freire's (2004) theory promoted an "understanding of history as opportunity and not determinism" and modelling hope by educators as "an act of moral imagination". Within this framework the integrity of teachers and students alike was built through mutual problem posing and dialogical engagement rather than a one way transmission of values or "depositing" readymade knowledge.

This kind of engagement of the pedagogical subjects is necessary as they are never educationaly homogeneous but 
mostly culturally diverse individuals. Freire saw an ethical imperative to cross borders of cultural identities and status. He understood integrity as persevering in seeking social justice, acting for empowerment and opposing any forms of oppression. Crossing the lines of difference through unprejudiced dialogue constituted the essence of social justice learning. Freirian "conscientização" as a process of social introspection requires the entire community of practice to develop the sense of integrity based on permanent ethical self-vigilance. Concientização enables the transformation of otherwise fixed structures through the dialogue as a tool of social agency.

\section{Literature review on academic integrity}

Academia's function is to engage the diversity of beliefs and methodologies to establish the truth (research), facilitate the dialogue on ways to tackle seemingly insurmountable issues (service) and determine who is qualified to meaningfully address these problems (teaching and accreditation, Cummings, 1998). To fulfil this mission universities and other higher education institutions must have transparent policies on their academic integrity so their leaders, faculty members, students and graduates may be trusted by all the stakeholders (Bretag, 2016).

The literature on academic integrity concerns the studies of the personality features of academics as virtuous researchers and ethical models as teachers (Macfarlane et al., 2014) but also it is interpreted in terms of the respect for human rights and dignity as agreed by multinational bodies (Fjellstrom, 2005). Articles on the ethics of teaching, research, and service from 57 different journals representing various fields and quality of higher education predominantly look at academic integrity in terms of its counterfeits. Dominating the reports are the breaches of integrity in research practice, especially fabrication of data and plagiarism, but also conflicts of interest in sponsoring research costs by commercial organizations. The literature about service, however, does include the constructive concept of aligning academic work with a dedication to values and to social responsibility (Berube, 1996). A list of prescriptive principles for academic ethical conduct is offered by some authors along with basic contextual factors which favour or hinder integrity in academia (Corlett, 2005). Many articles stress the importance of intercultural competences in perceiving and building academic integrity (Bryan et al., 2009) and call for their inclusion in the policies of universities.

The academic Integrity Standards Project (2012), (Bretag and Mahmud, 2014) re-defines the issue from the compliance with principles to actual education on what integrity entails. The study showed that while most stakeholders understood integrity in terms of misconduct and breaches, over $40 \%$ of students would like to see the shift to the constructive approach and academic culture that would promote integrity as social competency beyond academic life. $92 \%$ of students agreed that academic integrity has relevance to their lives in terms of professional qualifications and personal relations. Most stakeholders agreed that both value aspirations and documented best practices helped to develop stable cultures of integrity in specific universities. Such a culture must be grounded in action and promoted by everyday experiences rather than just remain on the level of declarations and codes of ethical behaviour on university websites. Action is understood as being both the brave defender of aspirations and human dignity against ideological adversity or corruptive status structures as well as being the passive witness to the misconduct. Recording and reflecting on the contexts of failures and breaches of integrity was indicated by $42 \%$ of project participants as crucial for learning positive attitudes and building the culture of integrity. While students have no problem understanding what integrity is NOT, they expect their faculty to help them to grow morally through creation of the added value for the academic and local community rather than just to avoid misconduct (Bretag et al., 2011).

The literature on academic integrity concerns the studies of personality features of academics as virtuous researchers and ethical models as teachers (Macfarlane et al., 2014) but also it is interpreted in terms of the respect for human rights and dignity as agreed by multinational bodies (Fjellstrom, 2005). Articles on the ethics of teaching, research, and service from 57 different journals representing various fields and quality of higher education predominantly look at academic integrity in terms of its counterfeits. Breaches of integrity in research practice, especially fabrication of data and plagiarism, but also conflicts of interest in sponsoring research costs by commercial organizations dominate the reports. The literature about service, however, does include the constructive concept of aligning academic work with dedication to values and social responsibility (Berube, 1996). A list of prescriptive principles for academic ethical conduct is offered by some authors along with basic contextual factors which favour or hinder integrity at academia (Corlett, 2005). Many articles stress the importance of intercultural competences in perceiving and building academic integrity (Bryan et al., 2009) and call for including them in both individual university's and in more general policies.

Academic Integrity Standards Project (Bretag and Mahmud, 2014) re-defines the issue from the compliance with principles to actual education on what integrity entails. The study showed that while most of stakeholders understood integrity in terms of misconduct and breaches over $40 \%$ of students would like to see the shift to the constructive approach and academic culture that promote integrity as social competency beyond academic life. In total, $92 \%$ of students agreed that academic integrity has relevance to their lives in terms of professional qualifications and personal relations. Most stakeholders agreed that both value aspirations and documented best practices helped to develop in specific universities stable cultures of integrity. Such culture must be grounded in action and promoted by everyday experiences rather than just declarations and codes of ethical behaviour on university websites. Action is understood both as brave defenses of aspirations and human dignity against ideological adversity or corruptive status structures as well as passivity and failure to prevent misconduct like disrespect to diversity, plagiarism, falsification of research, unjust assessment of learning, neglect to quality of teaching, etc. Recording and reflecting on the contexts of failures and breaches of integrity was indicated by $42 \%$ of project participants as crucial for learning positive attitudes and building the culture of integrity. While students have no problem understanding what integrity is NOT they expect faculty to help them grow morally and not just avoid misconduct but engage ethically in creating added value for the academic and local community (Bretag et al., 2011).

The definition worked out during the Australian project serves best the purpose of this study: "Academic integrity is a commitment, even in the face of adversity, to fundamental values: courage, honesty, trust, fairness, respect and responsibility. From these values flow principles of behaviour that enable academic communities to translate ideals into action" (Bretag, 2016: 4).

The research on assessment of teaching ethics (Ozar, 1998) shows that achieving learning outcomes depends on successful alignment of all didactic elements in the course: pedagogical paradigm, learning system, teachers' competences, choice of material, methods of teaching/learning and assessment. Some researchers (Bowden and Smythe, 2008) further argue that "a low level of importance be given to teaching moral or ethical theories, and in fact, such theory that is needed is easily acquired by a 
discipline based ethics teacher" (Bowden and Smythe, 2008). Finally the researchers list the whole of range of evidence supporting the use of experiential methods that best serve the objectives of integrity education. The most effective ones include live case studies, role playing and dialogical problem solving. Another updated list of methods includes role-reversal under the category of personal engagement which is advocated for further validation as world-wide practice. (Solymossy, 2015)

The most comprehensive EU supported research on the use of drama for improving educational competences (DICE projectDrama Improves Key Lisbon Competences in Education, www. dramanetwork.eu) provided both quantitative (5000 students) and qualitative (cases from 13 countries) evidence on how drama works as a complex didactics which allows the educators to become relators aligning dialogical pedagogy with progressive system, democratic choice of significant concepts and material with experiential techniques. The study examined over 100 international teachers using drama with youth and concluded that their universal strength was the ability to maximize learning by making it relational and inquisitive. They use drama because they believe it empowers the students to creatively explore life beyond imposed curricula, liberates the entire community of learners from the fear of educational failure installed by oppressive social structures (Heathcote, 1990). Even short-term drama sessions impacted students' level of competences, most effectively the social ones including ability to build and sustain trust, initiate enquiry to find out truth, critically choose and translate values into actions, respect diversity, take responsibility and learn from failures, engage in civic activities and mobilize peers to take risks to defend transparency, fairness and dignity (Jagiello-Rusilowski, 2010).

Some previous studies explored the potential of drama to reduce fear of performance and transform self-efficacy beliefs of youth into more constructive attitudes where beliefs on personal integrity are correlated with other educational competences. (Jagiello-Rusilowski, 2010a). It is important, however, that drama activities are aligned with other elements of didactics serving integrity development. Such activities are mostly based on highly interactive forms, preferably based on improvising around seemingly unsolvable problems and dilemmas. The sessions must also include reflective and debriefing techniques which encourage students to challenge inadequate ethical stances or choices revealed on the spot (Sims, 2002, 2004).

The key rationale for using drama for developing integrity is that it facilitates deep learning (Campbell, 1998). Divergent problems further complicated by dramatic positioning in and out of roles motivate the students to be inquisitive, critical and answerable for their own spontaneous choices. Drama engages students in dialogical relationships through which they are able to inductively discover innovative solutions and create new knowledge. Edging-in drama games and exercises result in group trust and willingness to share risks. Dramatic structures alternating between emotional engagement in role and rational distancing facilitate re-examining of ethical knowledge and stereotypical assumptions. Framing action and sequencing characters' dialogues help students deeper synthesize and challenge existing social principles to capitalize on diversity. More symbolic elements of drama allow their participants to express and organically experience solidarity and commitment to basic values which in turn impacts their ethical fibre (Edmiston, 2000). The debriefing questions in the form of reflective drama techniques allow the students to demonstrate deep comprehension of ethical dilemmas they had the chance to enact personally or observe and share experience with other players. The research suggests that unpredictable questions asked by the trusted community of learners elicit the most valuable educational outcomes (Harrison,
2004). The unique contribution of improvisation during drama sessions is the "no penalty" zone allowing any immediate response to be acknowledged and only later be reflected upon for its ethical implications for all the stakeholders of the particular encounter.

\section{The research project: problem, questions, groups and plan}

The above quoted research evidence shows that the development of integrity in the higher education context is facilitated by interventions which aim at collective transformation of social relations and structures rather than just prevention of counterfeits that occurred in the past through instalment of the mainstream ethical principles and the awareness of systemic sanctions. Successful instruction for students depends, therefore, both on the social context of ethical dialogism and criticism as well as the didactic competence to align the goals of integrity learning with the educational system, methods and validation of outcomes. The problem posed in this study concerns the potential of drama as the educational intervention to facilitate the development of integrity amongst the academic community members. The specific research questions were:

1. Does drama intervention change students' efficacy beliefs about their integrity?

2. Which outcomes of integrity learning are manifested most as a result of drama?

3. How students' use nominations of characters to make integrity meaningful

4. How sociometry as a validation of integrity learning outcomes reveals alignment of drama practices with dialogism and critical pedagogy

The hypothesis to the first question was that drama intervention raises self-efficacy beliefs of the students about their academic integrity. There were two groups of Master of Business Administration students who took part in a whole week long innovation camp in the same location in Finland. Each group had 30 students aged 21-38. Upon arrival at the innovation camp venue both groups were offered an introductory workshop in drama improvisation and then opted to continue the working on their assignments in this way or without any elements of drama. The students voted and the group who decided to use drama became the experiment group and the other who preferred to work with other innovation pedagogy methods like hatcheries (Penttilä et al., 2012) became the control one. Both groups were multicultural, the students came from 18 countries. The selfefficacy test was administered to both groups twice: at the input level, directly after the decision on the method adopted and at the output level after 6 days of collaborative work, presentations of the outcomes (pitching of innovation ideas) and the evaluation of the camp which for the experiment group only involved extra sociometry session. The experimental group was also asked to reflect on their integrity learning both during the drama practices and the sociometry session

\section{Self-efficacy beliefs test}

The test was designed according to socio-cognitive principles (Bandura, 1995) to capture the level of individual estimations of ability to perform imagined actions. The personal perceptions of efficacy predict student's future engagement in the questioned activity or avoidance strategies at all cost. The expected transformation of self- beliefs can be measured by the difference of scores for the students declared in 30 statements which all start with: I am able to ... The declarations coincide with 4 objectives of academic integrity course (1) sensitivity to what is ethically at 
stake (sentences nr:1, 3, 6, 16, 17, 18, for example,: I am able to express my concern when seemingly innovative solution may harm underprivileged group), (2) reasoning/reflective skills $(7,21,23,27$ e.g. I am able to argue why we should have transparent rules for getting public funding for change-makers) and (3) motivation/conviction to give over other considerations to the values that prompt the action that ought to be taken (sentences 2, 5, 8, 9, 10, for example, I am able to sacrifice time and risk failure rather than copy somebody's work even if my professors would have no way to find out), (4) strategizing to implement the course of ethical action. (sentences: 7, 11, 20, 22, 25 , 26, for example,: I am able to work patiently on trust in my team even if my peers seem unmotivated).

Students filling in the test on their self-efficacy about academic integrity had to indicate with a circle on the continuum below each sentence how strong they felt with each hypothetical manifestation of their integrity from 0 to 100 . The values were added up to give the total score of perceived self-efficacy. The similar design of the test was validated in the past by the author and in two cases the statistical results were compared with scores of simulations in which tested youth were challenged in teams with divergent problems requiring creative responses demonstrating emotional and cognitive skills or spontaneously negotiated ethical choices. The efficacy level expressed in the test predicts the potential engagement or avoidance of unpredicted social interactions (Jagiello-Rusilowski, 2010a) An analogical test on resilience was also used with the same group during the same camp. (Jagiello-Rusilowski, 2016)

\section{Sociometry and reflective narratives}

Sociometry is a quantitative tool which originated from the sociodrama practices (Moreno, 1956). Originally it was used to reveal the status of each member in the community of practice in terms of their popularity or isolation with the use of roles and characters to encourage reflection on attitudes in general rather than labelling individuals. Sociometry was further developed into a qualitative method to better capture the role of the context in which the social relations are examined. The complex arrangement of group factors with regards to ethical choices can be annualized in sociometry through the network images (Farmer and Farmer, 1996) or cognitive mapping (Avramidis and Wilde, 2009). The tool is capable of revealing both Bakhtin's dialogism and Frerian critical pedagogy because it allows the participants to respond not just to researcher's questions but more importantly to each other's positions, to distance themselves from prevailing structures or "chronotopes" and relate their choices to the benefit of a wider community.

In the study sociometric session the participants were asked to select some characters they had devised and role-played during the drama practices at the camp. Next they could re-imagine the characters in specific situations of adversity and improvise with each other how the characters would behave, reason, show ethical sensitivity, resilience and strategize to preserve the following values: honesty, courage, trust, respect and responsibility. The students were asked to nominate the characters several times to decide on each value and aspect of integrity behaviour known to them from the learning outcomes (Ozar, 1998). After each round the students could offer their personal reflection, insights or justification of the choice they made. They were encouraged to describe the process of exploring the different social and fictional roles they encountered, the motivations they had to engage in a particular role, the obstacles they perceived objectively for the character or subjectively from their personal experience, the failures to maintain hypothetical or real integrity and above all the satisfaction they felt in succeeding to keep in line with the values negotiated by the team during the improvised performances.

\section{Drama sessions as independent variable}

Drama was used with the experimental group as a series of activities in which students were encouraged to imagine "as if" they reacted in fictional space, time or characters in order to experience the interaction more comfortably and to reflect on the learning which took place. They were offered structures and departure situations which required high level of mindfulness and mutual care. Improvisational tasks made them focus on the problem and how fictional characters would try to solve it under the particular circumstances, rather than on presenting themselves as skilful performers and competent problem solvers. (Spolin, 1999). The "Golden Rule" of improvisation is unconditional acceptance (Gessel, 1997). Improvisers succeed in advancing the action only when they automatically say "yes" to a new idea from other players, explore its potential to continue with "yes, and ...," meaning, "I accept the offer to improvise (using ideas, words, or movement) and must build on it." This attitude facilitates attentive listening and collaboration. Each improviser is responsible for making the performance dramatic: develop the story-line, character motivation and amazing conclusions. The flow that the players experience may result in some creative and possibly novel strategies of action (Koppett, 2001).

The improvisation starters were either team designed or taken from actors' training books. For example:

\section{"Nr. 30 The scene: Two students are in a library working together on a research paper.}

Player one: You think it's OK to make up a few books' titles to include in your bibliography. You don't mind including a few phony footnotes, either

Player two: You like the problem of your research paper and could do with some help to find out the state of art and add some fresh ideas to the field. You wouldn't dream of using any fake books or footnotes" (Bernardi, 1992).

\section{Research results}

Efficacy test scores. There were no statistically significant differences between the control and experiment groups in their totals for belief in self-efficacy regarding academic integrity. This was revealed by the T-tests of the independent samples of the equality of means taken after the drama training. The only exception was a slight tendency towards higher scores in the cluster of motivation/conviction to give over other considerations to the values that prompt the action that ought to be taken (resilience-as shown in Table 1).

The students from experimental drama group had statistically stronger beliefs in the capacity to show courage in adversity

\begin{tabular}{|c|c|c|c|c|c|c|}
\hline & \multicolumn{3}{|c|}{ Experimental group n 30} & \multicolumn{3}{|c|}{ Control group n 30} \\
\hline & Input & Output & Mean dif. & Input & Output & Mean dif. \\
\hline $\begin{array}{l}\text { Overall test } \\
\text { score }\end{array}$ & 2087 & 2219 & 132 & 2132 & 2214 & 82 \\
\hline 1. Sensitivity & 637 & 680 & 43 & 615 & 582 & -33 \\
\hline 2. Reasoning & 903 & 918 & 15 & 912 & 921 & 9 \\
\hline 3. Resilience & 534 & 671 & 137 & 528 & 556 & 28 \\
\hline 4. Strategizing & 612 & 635 & 23 & 583 & 578 & -5 \\
\hline
\end{tabular}


(sentence 2), to admit failure to stay fair (sentence 5), to take responsibility for their own mistakes (sentence 8 ), to defend "the other" appreciating their diversity (sentence 9), and to give honest feedback to unfair professors (sentence 10). The cluster of commitment to values (resilience) was higher in the improvisation group $(t=1,894, p=48)$.

As Fig. 1 shows the mean value for the resilience cluster in the group using drama changed to a higher in the output measurement and the difference was the only significant compared to other clusters.

Sociometry. The participants of the experimental group selected key characters from the sessions in order to indicate to what extent they epitomize specific virtues and areas of integrity and offer their personal or their character's arguments, insights, dilemmas, which would demonstrate integrity. The results may be summarized as in the Table 2:

The participants' nominations were mapped and recorded as follows: Figure 2.

\section{Discussion of the results}

The self-efficacy test results did not support the hypothesis that drama practices raise the students' self-efficacy beliefs on their academic integrity. However, after comparing separately the clusters of statements related to being resilient a tendency in favour of the experimental group was identified. The evidence from the above presented research is not enough to generalize that drama intervention actually change students beliefs, however, thanks to the use of sociometry, it is possible to identify the outcomes of integrity learning which manifest through dramatic activity. Drama as a learning medium allows the alignment of elements of critical pedagogy and dialogism such as "moral imagination" and solidarity against oppression, relating the educational content to both the characters' and personal experiences, questioning the status-quo to embrace the diversity of perspectives revealed in improvisations and finally demonstration of the change in collective and individual attitude towards social justice. The nominations revealed the ability of the students to use their character work. Their nominations seemed consistent with the diagnosis of their self-efficacy in ethical reasoning (36 nominations) as high already at the input level. They also gave 33 nominations in the category of resilience but the choices were unevenly distributed between the characters based on the students' judgements which may indicate their heightened motivation and conviction to adhere to shared values especially in adverse circumstances. The remaining outcomes of drama as the integrity were not strongly manifested through the nominations while the values ascribed to the most frequently nominated characters matched the heightened awareness of resilience (courage and respect for self and others).

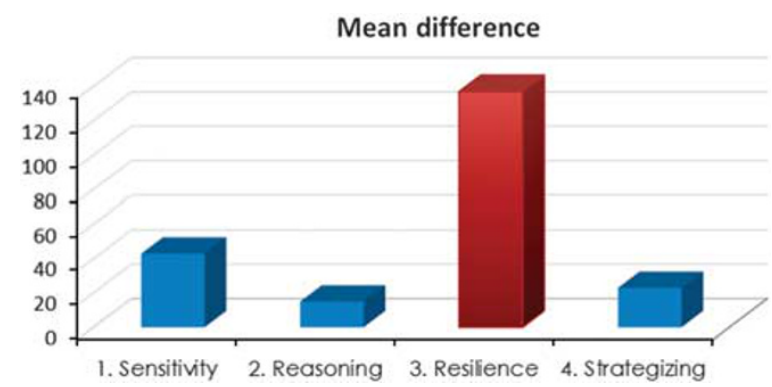

Figure 1 | Mean differences of clusters.
Drama elements used during an innovation camp for MBA students proved to be an effective way of increasing students' beliefs about their ethical stance: showing courage in adversity, admitting failure to stay fair, take responsibility for their own mistakes, defending "the other", appreciating diversity and giving honest feedback to unfair professors. Since the level of beliefs on self-efficacy predict subjects' level of engagement or distancing from declared behaviours, even a slight raise in its level will translate into meaningful changes of personal attitudes. In this case it is an attitude crucial for development of integrity in terms of giving over some ego driven considerations (like personal gains or even safety) to group negotiated values.

While MBA students in general seemed to be unaffected by any activities during the innovation camp in their beliefs on academic integrity the group that opted for improvisational exploration of ethically challenging situations showed more optimism about their courage in face of adversity. Their commitment to fairness was visibly changed by their experience of the flow of ideas, their observations of the collective decision-making process, strategizing while being together in the event, the orientation of the tasks and their feelings of solidarity. What is impressive in the cluster of integrity beliefs is that it includes the courage to admit failures, to be consistent in declaring their values and acting on them. Integrity in the context of academic life seems to be meaningful and learnable for the MBA students not so much as the knowledge of moral principles and under which circumstances they are violated but rather in terms of being answerable to oneself and others for specific moral choices. To admit that one made a mistake and disappointed oneself as well as hurt others seems equally brave as telling the authority that they are unfair. Both capabilities are learnt through dialogical engagement with diverse perspectives and drama improvisations seem to provide enough opportunities for testing students' answerability and ethical self-vigilance, at least in hypothetical and dynamic contexts.

The researched groups were very assertive in their evaluations of academic integrity, especially in terms of its breaches. The MBA students came from different countries but from their top universities with already an impressive academic record and business experience. Most of them were familiar with ethical codes of their own universities and knew how to avoid misconduct. Their self-efficacy beliefs on academic integrity allowed them to engage with diversity and creativity to find ethically sound innovative business solutions. Still the study shows that their academic integrity had space for improvement. Through drama interventions they became more open to changes in their attitudes towards admitting failures and dilemmas of maintaining integrity in the face of adversity or pressures from authority to adhere to status rather than values.

Their choices in the sociometry and reflective narratives reveal more interesting insights into how improvisation worked for their ethical development. As MBA students regardless of their cultural background and differences they feel obliged to assume the role of a ruthless leader with the aura of utter success, immune to any values that might stand in the way of winning over the competition. The self-designed characters and their "whys", which required truly creative approaches and solutions resulting from the synergy of the team players allowed them explore the illdefined integrity problems by engaging in free dialogues, experiencing the fear of making a mistake, appearing unethical, and being incompetent or dull in the most safe "no penalty zone" environment.

Their nominations during the sociometry stand for their ability to identify the four areas of integrity as learning outcomes. Without memorizing any theories they could easily and 


\section{Table 2 | Exemplifications of improvised characters of integrity (own material)}

\begin{tabular}{|c|c|c|c|}
\hline characters and their "why" & aspects of integrity exemplified & commitment to values & $\begin{array}{l}\text { new insights on integrity for MBA } \\
\text { students }\end{array}$ \\
\hline $\begin{array}{l}\text { battleship engineering } \\
\text { student fobbed off by a } \\
\text { professor }\end{array}$ & $\begin{array}{l}\text { moral reasoning: "I need feedback so I } \\
\text { can learn to construct battleships } \\
\text { which deter enemy attacks" }\end{array}$ & $\begin{array}{l}\text { feeling responsible for national security, } \\
\text { preventing violence courage to challenge } \\
\text { authority/status }\end{array}$ & $\begin{array}{l}\text { Once you believe constructing } \\
\text { battleships is ethical you must learn } \\
\text { to build them well not just get a } \\
\text { diploma }\end{array}$ \\
\hline $\begin{array}{l}\text { whistleblower losing a job } \\
\text { for revealing racism in } \\
\text { academia }\end{array}$ & $\begin{array}{l}\text { sensitivity to what is at stake: "There is } \\
\text { no innovation without diversity". "I } \\
\text { will not be loyal to racist organization" }\end{array}$ & respect for diversity & $\begin{array}{l}\text { Once a member of academia and } \\
\text { committed to innovation you fight for } \\
\text { diversity }\end{array}$ \\
\hline $\begin{array}{l}\text { Investor in medical start up } \\
\text { demanding } 80 \% \text { shares in } \\
\text { profit }\end{array}$ & $\begin{array}{l}\text { strategizing capabilities to implement } \\
\text { the course of action }\end{array}$ & $\begin{array}{l}\text { trust: "I risk all my assets to support } \\
\text { young innovators-without my help they } \\
\text { will be blocked by pharmaceuticals" }\end{array}$ & $\begin{array}{l}\text { Consistent investor has the right to } \\
\text { profit. Integrity is about believing in } \\
\text { change-makers ignored by power } \\
\text { structures }\end{array}$ \\
\hline $\begin{array}{l}\text { Philosopher admitting self- } \\
\text { plagiarism }\end{array}$ & $\begin{array}{l}\text { conviction to give over considerations } \\
\text { of representing a group modelling } \\
\text { integrity to honesty }\end{array}$ & $\begin{array}{l}\text { honesty, courage "Statistically } \\
\text { philosophers most rarely admit } \\
\text { counterfeits - I want to challenge that }\end{array}$ & $\begin{array}{l}\text { Integrity is ability to deal with failure } \\
\text { and take responsibility for own } \\
\text { actions to ensure credibility }\end{array}$ \\
\hline
\end{tabular}
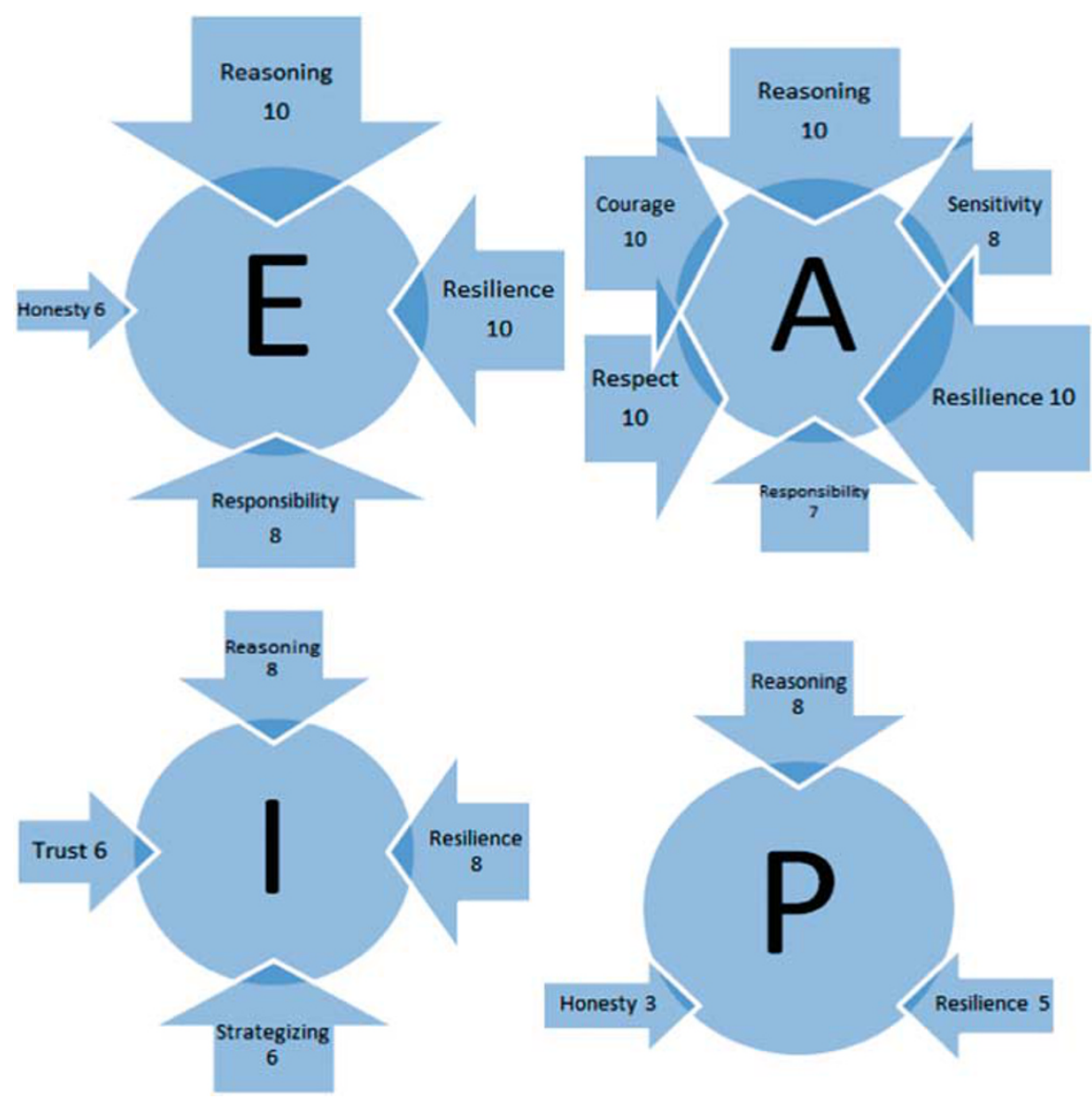

Figure 2 | Nomination mapping of the characters: Engineer (E), Anti-racist (A), Investor (I) and Philosopher (P).

spontaneously identify all the aspects of academic integrity as well as define it in terms of commitment to the fundamental values.

Academic integrity means expecting the best of themselves and fellow students as well as motivating their professors to take responsibility for how levels of competency will affect the global society. The group chose the character of the engineering student who hoped to invent a new battleship but became a nuisance to his professors. They simulated a highly humorous scenario about building a ship that would not actually move but then reflected more seriously on the need for committing to whatever qualifications you aspire for. In many senses integrity at the academic level may affect global security or development.

The research group became very emotional and committed to developing academic integrity as the safeguard of respect for diversity. They showed strong solidarity in their expectations of academia to be free from any form of racism. The choice of 
"whistleblower" proved their increased readiness to object to discrimination both on human rights grounds, where some of the assumptions of Western students were challenged by non-EU participants of the camp, but also from the perspective of their mission to be global change makers. In their view integrity is the pre-condition for engaging in innovation which is powered by diversity, collaboration beyond narrow national or discipline divides.

The most intriguing insights were offered by MBA students who chose an overtly greedy investor as a character of integrity. The meaning of academic integrity was extended to a sponsor of medical research who was consistent with his commitment to valuing change-making solutions at high financial stakes. Profiting from innovations that save lives was interpreted as ethical after a series of emotional improvisations which showed the shifts in positions and evaluations of stakeholders actions. Finally, consistent with the self-efficacy test results, the students featured the character of a philosopher who had the courage to admit selfplagiarism. The essence of academic integrity is confirmed here: it is about ethics from within, the power of it is in honesty even at the cost of losing academic status. Integrity should not become a marketing tool but the fabric of academia as one of the few remaining fortresses promoting intercultural dialogue on how knowledge should be created to serve the global development. The character work and reflection around his actions released many reservations and fears of taking specific ethical positions. MBA students admitted their apprehension of the subject itself and how they were afraid of judging and being judged ethically by peers. They admitted that it was safe to exchange even the most complex philosophical views in general but it was frightening to take a role and reveal the workings of the inner mind in terms of its integrity. The insights into more personal meanings of integrity suggest that the MBA students focussed on finding consistency in their characters' beliefs, actions and their perceptions of social contexts. Integrity for them means being able to enter an inner and communal dialogue on what is at stake ethically and what needs and values the specific community prioritizes.

\section{Conclusions}

The research results show both the potential of drama as well as its limitations for developing integrity in the context of innovation training of university students. Drama offered in this specific instance, however, appears to enable the facilitators to align educational methods along dialogism and critical pedagogy to fulfil the students' expectations to know what integrity entails beyond avoiding misconduct against academic standards. Drama work has added value for them in communal experience of negotiations of shared values and mechanisms of ethical selfvigilance. Working with the perspective of a character and distancing tools allowed the students to switch off their strong ego defenses, become more mindful and able to exchange ethical perspectives but more importantly become aware of emotions either limiting or enhancing self-efficacy beliefs about their integrity. Drama allowed the MBA students to re-define the academic or corporate integrity from just another element of competitiveness to the core of individual and collective accountability. They developed a necessary distance to failure to keep integrity under certain circumstances. They stressed that improvisation training was experienced as a form of therapy rather than formal learning and social responsibility display. Instead of insisting on being models of integrity they could enjoy full integration with the group by sharing their own dilemmas, adapting and capitalizing on the perspectives of co-created fictional constructs. Drama improvisation meant safe and positive interdependence, relief from the pressure of personal decisions which affect a collective sense of integrity. It also helped the MBA students to break free from harmful self-censorship which might prevent the expression of diversity and a reluctance to take superficially understood integrity risks. They praised patience and serenity as the result of practicing YES AND approach which helped them to avoid premature judgement or discard any peers appearing unethical.

The value of drama in developing integrity in higher education contexts lies in its potential to explore multiple perspectives and learning from imaginary dialogues with characters who may take ethically doubtful positions. The fear of making a mistake is reduced by a focus of eventfulness itself and a collective commitment to finding a solution that satisfies the needs for keeping the integrity of all the subjects involved. Both students and faculty are able to explore through drama what would happen if their actions ranged along the full spectrum from ideal integrity to the worst imaginings of its counterfeits. While traditional university policies and educational programs of integrity development focus excessively on ethical misconduct and its individual legal or collective reputation consequences, drama training offers implementation of a more intercultural and dialogical understanding of integrity. Bakhtin's concepts of "answerability" and "outsidedess" seem to work well for explaining the processes which take place during the drama sessions and result in increased perceived efficacy in on adhering to basic values even in the face of adversity. Students become more assertive about their own ethical choices if they experience a safe educational environment in which they can improvise in roles various responses to unfolding events and their socially constructed meanings. Drama was used previously at universities for retrospective analyses of ethical misconduct or heroic moral acts but this study may open up its novel applications for truly Bakhtinian dialogical learning through the living experience of the unique event, which allows the integration of thoughts, feelings, words, and gestures for which one takes responsibility and towards which one orients one's strategy, first in imaginary but afterwards also in working life situations.

The study faced some difficult methodological challenges as testing personal beliefs on sensitive issues like integrity were underestimated by the author. Quantative approach proved useful in a limited capacity to reveal only one aspect of integrity development through drama. Future efforts will focus on better planning of the research design to include more rigorous qualitative tools. Sociomentry proved to be more than a measurement tool. It revealed the workings of dialogism and critical pedagogy translated into drama interventions for building integrity beyond students' resilience. It could have been the part of drama practice so the debriefing stage of integrity learning could be more fully captured in the self-efficacy testing. The future research could add to the higher education practices for teaching integrity self-vigilance through drama uses in response or ideally in tune with the already existing strong policies on ethical standards of academic communities.

\section{References}

Academic Integrity Standards Project (2012) http://www.aisp.apfei.edu.au/.

Avramidis E and Wilde A (2009) Evaluating the social impacts of inclusion through a multi-method research design. Education; 3-13 (37): 323-334.

Bandura A (1995) Self-efficacy in Changing Societies. New York: Cambridge University Press.

Babbitt SE (1997) Personal integrity, politics and moral imagination. In: Brennan S, Isaacs T and Milde M (eds). A Question of Values: New Canadian Perspectives 
on Ethics and Political Philosophy 1997. Rodopi: Amsterdam, The Netherlands; Atlanta, GA, pp 107-131.

Bakhtin MM (1986) Speech Genres and Other Late Essays. University of Texas Press: Austin, TX.

Bakhtin MM (1990) Art and Answerability. University of Texas Press: Austin, TX. Bauman Z (2001) Identity in the globalizing world. Social Anthropology EASA; 9: 121-129.

Bernardi P (1992) Improvisation Starters. Betterway Books: Cincinati, OH

Berube M (1996) Public perceptions of universities and faculty. Academe; 82 (4): 10.

Bowden P and Smythe V (2008) Theories of teaching and training in ethics. Journal of Business Ethics and Organization Studies; 13 (2), http://ejbo.jyu.fi.

Bretag T (2016) Handbook of Academic Integrity. Springer.

Bretag T and Mahmud S (2014) A conceptual framework for enacting exemplary academic integrity policy. Studies in Higher Education; 7 (2).

Bretag $\mathrm{T}$ et al (2011) Core elements of exemplary academic integrity policy in Australian higher education. International Journal for Educational Integrity; 7 (2): $3-12$.

Bryan LD, Yahr MA and Schimmel K (2009) Perceptions of college and university codes of ethics. Journal of Academic and Business Ethics; 2 (3): 1.

Campbell E (1998) Teaching Strategies to Foster Deep versus Surface Learning. University of Ottawa, Center for University Teaching: Ottawa, Canada.

Corlett JA (2005) The good professor. Journal of Academic Ethics; 3 (3): 27.

Cummings WK (1998) The service university movement in the US: Searching for momentum. Higher Education; 35 (1): 69-90.

DICE project-Drama Improves Key Lisbon Competences in Education, www. dramanetwork.eu.

Edmiston B (2000) Drama as ethical education. Research in Drama in Education; 5 (1).

Fjellstrom R (2005) Respect for persons, respect for integrity. Medicine, Health Care and Philosophy; 8 (2): 231-242.

Farmer TW and Farmer EMZ (1996) Social relationships of students with exceptionalities in mainstream classrooms: Social networks and homophiles. Exceptional Children; 62, 431-450.

Freire P (2004) Pedagogy of Hope. A\&C Black, p 77.

Gesell I (1997) Playing Along 37 Group Learning Activities. Whole Person Associates: Duluth, MN.

Handley WR (1993) Bakhtin carnival and other subjects, Amsterdam-Atlanta. Critical Studies; 3 (2).

Harrison P (2004) Unleashing deep learning through questioning. Paper presented at the Education in a Changing Environment Conference, University of Salford, UK.

Heathcote D (1990) Collected writings on education and drama. In: Johnson L and O’Neil C (eds). Evanstone: Stanley Thornes Publishers.

Jagiello-Rusilowski A (2010) Bunch meaning business (in) Making a World of Difference, A DICE resource for practitioners on educational theatre and drama, Belgrade, Bergen, Birmingham, Brussels, Bucharest, Budapest, Gaza, Gdansk, Lisbon, Ljubljana, Prague, Umea, Wegeningen, DICE Consortium.

Jagiello-Rusilowski A (2010a) Drama in promoting social competences (in) Drama w Stopklatce-w kierunku pozytywnej zmiany spolecznej, Warszawa.

Jagiello-Rusilowski A (2016) Improvisation in revealing and developing hidden competences, INTED2016 Proceedings IATED Digital Library.
Koppett K (2001) Training to Imagine: Practical Improvisational Theatre Techniques to Enhance Creativity, Teamwork, Leadership, and Learning. Stylus: Sterling, VA.

Macfarlane B, Zhang J and Pun A (2014) Academic integrity: A review of the literature. Studies in Higher Education; 39 (2): 339-358.

MacIntyre A (1981) After Virtue. Duckworth: London.

Moreno JL (1956) Sociometry and the Science of Man. Beacon: New York.

Ozar DT (1998) An outcomes-centered approach to teaching public-sector ethics. In: Bowman J and Menzel D (eds). Teaching Ethics and Values in Public Administration Programs. State University of New York Press: Albany, NY.

Pappas NJ (2015) Belief and Integrity: Philosophical Dialogues.

Penttilä T, Jagiello-Rusilowski A and Kairisto-Mertanen L (2012) Validating Social Competences as Learning Outcomes of Innovation Pedagogy (in) Proceedings of Conference on Engineering Education (INNER 23).

Robinson A (2011) In Theory Bakhtin: Dialogism, Polyphony and Heteroglossia, https://ceasefiremagazine.co.uk/in-theory-bakhtin-1/, accessed 5 January 2017.

Sims R (2002) Teaching Business Ethics for Effective Learning. Quorum Books: Westport, CT.

Sims RR (2004) Business ethics teaching: Using conversational learning to build an effective classroom learning environment. Journal of Business Ethics; 49 (2): 201.

Scherkoske G (2012) Leading a Convincing Life: Integrity and the Virtues of Reason. Cambridge University Press: New York.

Solymossy E (2015) Call for collaboration in researching the best practices in teaching ethical entrepreneurship: the conflict of money and ethics. Journal of Global Entrepreneurship Research; 5, 20. doi:10.1186/s40497-015-0036-5.

Spolin V (1999) Improvisation for the Theatre: A Handbook of Teaching and Directing Techniques, 3rd ed., Northwestern University Press: Evanston, IL.

\section{Data availability}

All data generated or analysed during this study are included in this published article.

\section{Additional information}

Competing interests: The author declares that there are no competing interests.

Reprints and permission information is available at http://www.palgrave-journals.com/ pal/authors/rights_and_permissions.html

How to cite this article: Jagiello-Rusilowski A (2017) Drama for developing integrity in Higher Education. Palgrave Communications. 3:17029 doi: 10.1057/palcomms.2017.29.

Publisher's note: Springer Nature remains neutral with regard to jurisdictional claims in published maps and institutional affiliations.

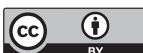

This work is licensed under a Creative Commons Attribution 4.0 International License. The images or other third party material in this article are included in the article's Creative Commons license, unless indicated otherwise in the credit line; if the material is not included under the Creative Commons license, users will need to obtain permission from the license holder to reproduce the material. To view a copy of this license, visit http://creativecommons.org/licenses/by/4.0/ 